Document downloaded from:

http://hdl.handle.net/10251/146163

This paper must be cited as:

Da Silva, SW.; Heberle, AN.; Santos, AP.; Rodrigues, M.; Valentín Pérez-Herranz;

Bernardes, A. (2018). Antibiotics mineralization by electrochemical and UV-based hybrid processes: evaluation of the synergistic effect. Environmental Technology.

https://doi.org/10.1080/09593330.2018.1478453

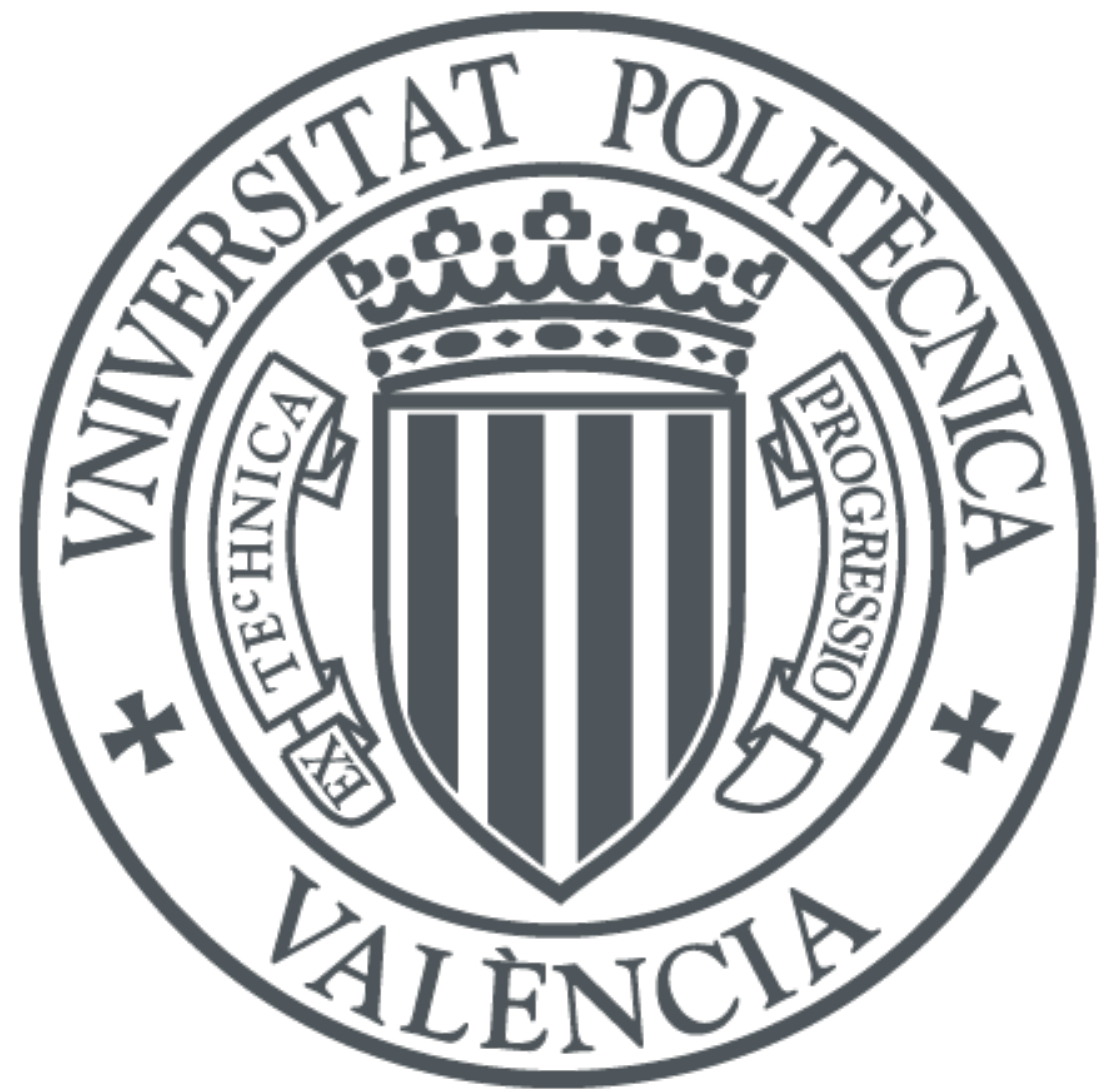

The final publication is available at

https://doi.org/10.1080/09593330.2018.1478453

Copyright Taylor \& Francis

Additional Information 


\section{Antibiotics mineralization by electrochemical and UV-based hybrid processes: evaluation of the synergistic effect}

\section{Salatiel Wohlmuth da Silva, Alan Nelson Arenhart Heberle, Alexia Pereira Santos, Marco Antônio Siqueira Rodrigues, Valentín Pérez-Herranz \& Andréa Moura Bernardes}

To cite this article: Salatiel Wohlmuth da Silva, Alan Nelson Arenhart Heberle, Alexia Pereira Santos, Marco Antônio Siqueira Rodrigues, Valentín Pérez-Herranz \& Andréa Moura Bernardes (2018): Antibiotics mineralization by electrochemical and UV-based hybrid processes: evaluation of the synergistic effect, Environmental Technology, DOI: 10.1080/09593330.2018.1478453

To link to this article: https://doi.org/10.1080/09593330.2018.1478453

Accepted author version posted online: 17 May 2018.

Submit your article to this journal $₫$

a)

View related articles $\sqsubset$

View Crossmark data $\asymp$ 
Publisher: Taylor \& Francis \& Informa UK Limited, trading as Taylor \& Francis Group

Journal: Environmental Technology

DOI: $10.1080 / 09593330.2018 .1478453$

Check for updates

Antibiotics mineralization by electrochemical and UV-based hybrid processes: evaluation of the synergistic effect

Salatiel Wohlmuth da Silva', Alan Nelson Arenhart Heberle', Alexia Pereira Santos', Marco Antônio Siqueira Rodrigues ${ }^{2}$, Valentín Pérez-Herranz ${ }^{3}$, Andréa Moura Bernardes ${ }^{1}$

1 Universidade Federal do Rio Grande do Sul (UFRGS) - Programa de Pós-Graduação em Engenharia de Minas, Metalúrgica e de Materiais (PPGE3M). Av. Bento Gonçalves, 9500, Porto Alegre/RS, Brasil.

${ }^{2}$ Universidade Feevale, Campus II ERS-239, 2755, Novo Hamburgo, RS, Brasil.

${ }^{3}$ Grupo IEC. Departamento de Ingeniería Química y Nuclear, E.T.S.I. Industriales, Universitat Politècnica de València. P.O. Box 22012, E-46071 Valencia, Spain.

Corresponding author*: salatielws@gmail.br, +55 5133089428

\begin{abstract}
Antibiotics are not efficiently removed in conventional wastewater treatments. In fact, different Advanced Oxidation Process (AOPs), including ozone, peroxide, UV radiation, among others, are being investigated in the elimination of microcontaminants. Most of AOPs proved to be efficient on the degradation of antibiotics, but the mineralization is on the one hand not evaluated or on the other hand not high. At this work, the UV-based hybrid process, namely Photo-assisted electrochemical Oxidation (PEO), was applied aiming the mineralization of microcontaminants such as the antibiotics Amoxicillin (AMX), Norfloxacin (NOR) and Azithromycin (AZI). The influence of the individual contributions of Electrochemical Oxidation (EO) and the UV-base processes on the hybrid process (PEO) were analyzed. Results showed that AMX and NOR presented higher mineralization rate under Direct Photolysis than AZI due to the high absorption of UV radiation. For the EO processes, a low mineralization was found for all antibiotics, what was associated to a mass transport limitation related to the low contaminants concentration ( $200 \mu \mathrm{g} / \mathrm{L})$. Besides that, an increase in mineralization was found, when HP and EO are compared, due to the influence of
\end{abstract}


UV radiation that overcome the mass transport limitations. Although the UV-based processes control the reaction pathway that leads to mineralization, the best results to mineralize the antibiotics were achieved by PEO hybrid process. This can be explained by the synergistic effect of the processes that constitute them. A higher mineralization was achieved, what is an important and useful finding to avoid the discharge of microcontaminants in the environment.

Keywords: UV-based processes; electrochemical oxidation; hybrid process; photo-assisted electrochemical oxidation; antibiotics.

\section{INTRODUCTION}

Among the wide range of anthropogenic contaminants that reach the water bodies, the pharmaceutical active compounds (PhACs) are the microcontaminants most present in the environment. PhACs, including antibiotics, are present in municipal wastewater, largely as a result of human excretion [1], intentional disposal of unused medicinal products in wastewater [2] and veterinary use [3]. It is important to highlight that wastewater from the pharmaceutical industry may have an important impact on the pollution of water bodies.

Some antibiotics groups have been widely found in surface waters, including macrolides (Azithromycin and Erythromycin), which have been added to the European Union watch list [4], fluoroquinolones (Norfloxacin, Enrofloxacin and Ciprofloxacin) [5] and $\beta$-lactam (Amoxicillin and its hydrolysis products) [6]. The presence of antibiotics in wastewater, even in low concentrations (ng/L or $\mu \mathrm{g} / \mathrm{L}$ ), has led to microbial resistance, representing a serious and growing threat to human health and wildlife in terrestrial and/or aquatic environments. In fact, the research by Barcelo and Bennett [7] confirms the idea that the overuse and misuse of antimicrobials led to the selection of resistant microorganisms to drugs.

According to Larsen et al. [8], the conventional wastewater treatment plants (WWTPs) are not originally designed for the elimination of microcontaminants, and their capacity to degrade this type of compound is not manly associate to mineralization, but rather to the degradation or absorption on activated sludge. In fact, it is consensual that the effluents from WWTPs are one of the main pathways for the introduction of PhACs into the environment [9]. Considering this problem, Advanced Oxidation Technologies (AOT) have been proposed for the elimination of PhACs from wastewater. 
Many studies were carried out to the degradation of antibiotics by photodegradation [10], photocatalysis [11], Fenton-like process [12], ozone and biological treatment system [13] and electrochemical [14] methods. However, these studies did not evaluate the microcontaminants mineralization.

In this context, the mineralization of microcontaminants by UV-based and electrochemical processes has been studied at this work. Direct photolysis (DP), heterogeneous photocatalysis (HP), electrochemical oxidation (EO), and an hybrid process, namely Photo-assisted electrochemical oxidation (PEO), were evaluated to the mineralization of the antibiotics amoxicillin (AMX), norfloxacino (NOR) and azithromycin (AZI) present in aqueous solutions at $\mu \mathrm{g} / \mathrm{L}$.

By direct photolysis the organic compound could be degraded by the absorption of a photon, resulting in bond cleavage or rearrangement to form a new stable product. This technique is commonly used for PhACs degradation in wastewater due to the high effectiveness and no limitations on mass transport $[15,16]$. However some studies have pointed out that the use of DP processes in the degradation of some PhACs leads to a high byproduct formation [17-19].

The combination of direct photolysis with a catalyst $\left(\mathrm{TiO}_{2}, \mathrm{ZnO}_{2}, \mathrm{WO}_{2}, \mathrm{Bi}_{2} \mathrm{O}_{5}\right.$ among others) can reduce the byproduct formation, achieving the mineralization by the hydroxyl radical ( $\left.\mathrm{HO}^{\bullet}\right)$. To the $\mathrm{HO}^{\bullet}$ generation, the catalyst need be photo excited, being an electron promoted from the valence band $(\mathrm{VB})$, where a hole $\left(\mathrm{h}^{+}\right)$is generated, to the conduction band (CB). The hole-electron gap generates reducing and oxidizing sites, which are able to catalyze chemical reactions ( $\mathrm{HO}^{\bullet}$ formation) [20]. However, the heterogeneous photocatalytic process has two major limitations; the hole-electron recombination and mass transport limitations, thereby causing effects on the reaction rate and on the energetic efficiency [21].

Electrochemical technology can be also considered an option in the antibiotic degradation [22] without chemicals use, generating in situ $\mathrm{HO}^{\bullet}$ on the surface of special anode materials, such as boron doped diamond (BDD) $[23,24]$. The main disadvantage of the electrochemical technology is the mass transport limitation, which can reduce the efficiency of PhACs removal. Although the use of BDD anode is very promising, problems related to diamond film stability, $\mathrm{sp}^{3} / \mathrm{sp}^{2}$ ratio and price may restrict its application [25]. On the other hand, Metal Mixed Oxides $\left(\mathrm{MO}_{\mathrm{x}}\right)$ may be an option due to their commercial availability, low cost and electrochemical stability [26, 27]. In addition, the mass transport limitation can be overcome if the $\mathrm{MO}_{\mathrm{x}}$ is irradiated with UV light [28-30]. 
In this context, the Photo-assisted electrochemical oxidation can be seen as an alternative for this issue. This is an hybrid process and uses a $\mathrm{MO}_{\mathrm{x}}$ anode such as $(70 \%-30 \%) \mathrm{TiO}_{2} \mathrm{RuO}_{2}-\mathrm{Ti}$ that enables the electrochemical oxidation to be photo-assisted by heterogeneous photocatalysis, increasing the $\mathrm{HO}^{\bullet}$ generation and reducing the hole-electron recombination [29].

Therefore, in the present work, the PEO process using (70\%-30\%) $\mathrm{TiO}_{2} \mathrm{RuO}_{2}-\mathrm{Ti}$ was studied aiming the mineralization of the antibiotics Amoxicillin (AMX), Norfloxacin (NOR) and Azithromycin (AZI). The individual contributions of Direct Photolysis (DP), Electrochemical Oxidation (EO) and Heterogeneous Photocatalysis (HP) were also evaluated. Additionally, the main influencing factors, such as direct or mediated oxidation, fluence rate, reaction kinetics and energy consumption were also assessed.

The main objective of this work is to develop a technical approach to obtain a high mineralization rate of antibiotics present at low concentrations in water.

\section{MATERIALS AND METHODS}

The general experimental flowsheet used in this work is presented on figure 1.

\section{FIGURE 1}

The stock solution used in the experiments was prepared with $100 \mathrm{mg} / \mathrm{L}$ of Amoxicillin trihydrate (AMX), Norfloxacin (NOR) or Azithromycin dihydrate (AZI) (>99\%, purchased from local pharmacy) in distilled and deionized water at $\mathrm{pH} 4$. The work solutions were prepared by diluting the stock solution to a final concentration of $200 \mu \mathrm{g} / \mathrm{L}$. This concentration was chosen based on the literature [31-33], and represents the usual AMX, NOR and AZI concentration in the wastewater of the pharmaceutical industry. Due to the low electrical conductivity of the solution, $2 \mathrm{~g} / \mathrm{L}$ of $\mathrm{Na}_{2} \mathrm{SO}_{4}(>99 \%$, Merck) was added as a support electrolyte in all work solutions.

\subsection{SOLUTION CHARACTERIZATION}

A chemical and an electrochemical characterization of the solution were carried out.

\subsubsection{Electrochemical characterization}


Cyclic voltammetry (CV) experiments with the stock solutions were accomplish in order to evaluate the influence of the direct and/or indirect oxidation in the electrochemical and photoassisted electrochemical process. The electrochemical measurements were obtained with or without UV radiation by using a $250 \mathrm{~W}$ high-pressure commercial mercury vapor lamp (HPL-N). All experiments were carried out using a three-electrode cell, where the work electrode was a $\mathrm{MO}_{\mathrm{x}}$ one, (70-30\%) $\mathrm{TiO}_{2} \mathrm{RuO}_{2}-\mathrm{Ti}$ with geometric area of $1.5 \mathrm{~cm}^{2}$, platinum $(\mathrm{Pt})$ was used as counter electrode and $\mathrm{Ag} / \mathrm{AgCl}$ (saturated) was applied as a reference electrode. The $\mathrm{CV}$ experiment was carried out between 0 and $1.5 \mathrm{~V}$, starting and finishing at the $0 \mathrm{~V}$ at a scan rate of $50 \mathrm{mV} / \mathrm{s}$. The potentiostat used was the Autolab PGSTAT302 potentiostat/galvanostat. A scheme of the threeelectrode cell is exhibited in figure S1 in the supplementary content.

\subsubsection{Chemical characterization}

The spectra of the antibiotics AMX, NOR and AZI (100 mg/L) were obtained by using UV/Vis spectroscopy (T80+UV/Vis Spectrometer from PG Instruments Ltd).

The $\mathrm{pH}$ was measured by potentiometric method using a DM-22 Digimed.

Mineralization was followed by total organic carbon (TOC) decay, determined on a Shimadzu TOC-LCPH equipped with an automatic sample injector. The analyses were carried out using a high sensitivity analysis kit to measure trace amounts (commonly $0.5 \mathrm{mg} / \mathrm{L}$ or less) by thermal catalytic oxidation at $680^{\circ} \mathrm{C}$ with a continuous supplying of oxygen flow (6.0). The nonpurgeable organic carbon (NPOC) method was used and the NPOC values represent the average of five measurements. All procedures was done according Shimadzu standard manual.

\subsection{Solutions treatment assays}

\subsubsection{UV radiation measurements}

To characterize the photo-based treatment assays, measurements of the spectral irradiance of UV-C and off the UV irradiation absorbed by the solution and arriving the catalyst surface were accomplished.

A Spectrometer Princeton Acton Spectra Pro 2300, equipped with a photomultiplier, was used to analyze the spectral irradiance of the 250 W HPL-N lamp in UV-C spectra. 
For the $250 \mathrm{~W}$ HPL-N lamp, in the UV-C spectra, the UV radiation $\left(E\right.$, in $\left.\mathrm{W} / \mathrm{m}^{2}\right)$ was measured on the anode/catalyst surface when ultrapure water or the initial solution containing AMX, NOR or AZI fulfill the reactor, by an Instrutherm MRUR-203 UV light meter.

The exposure time $\left(E_{t}\right)$ of the solution to the PEO processes was determined according to equation:

$E_{t}=t_{s} \times V_{r} / V$

where $t_{s}$ is the final treatment time in seconds (21600), $V_{r}$ is the reactor volume (2 L) and $V$ is the reservoir volume $(5 \mathrm{~L})$.

Using the equation 1 , the $E_{t}$ was calculated resulting in $8640 \mathrm{~s}$ (144 min), i.e. of the total treatment time of $360 \mathrm{~min}$, the solution remained under UV radiation only by $144 \mathrm{~min}$.

Thereafter, with the results of $E$ measurement in the anode surface and $E_{t}$ calculated, it is possible to calculate the Fluence rate $\left(\mathrm{kj} / \mathrm{m}^{2}\right)$ using the equation $(11)$ :

$F=E \times E_{t}$

\subsubsection{Treatment methods}

The setup of the reactor used in the PEO assays was already used in a previous work [30] and consisted of a jacket borosilicate glass reactor with a capacity of $2 \mathrm{~L}$, operated in batch mode connected to a $5 \mathrm{~L}$ reservoir. An ultra-thermostatic bath was used to control the temperature. The anode was the metal mixed oxide $\left(\mathrm{MO}_{\mathrm{x}}\right)$ and composed of $(70-30 \%) \mathrm{TiO}_{2} \mathrm{RuO}_{2}$ - $\mathrm{Ti}$ with geometric area of $475.2 \mathrm{~cm}^{2}$. The cathode was composed of $\mathrm{TiO}_{2}-\mathrm{Ti}$ with geometric area of $118 \mathrm{~cm}^{2}$. The electrodes were placed concentrically with a gap between electrodes of $0.5 \mathrm{~cm}$ around the 250 W HPL-N lamp without the glass bulb and inside a quartz tube, remaining under UV radiation. A current of $10 \mathrm{~mA} / \mathrm{cm}^{2}$ was applied on the electrodes by a CEL P-6000. $5 \mathrm{~L}$ of the initial solution were placed in the reservoir that feeds the reactor at an average flow rate of $1 \mathrm{~L} / \mathrm{min}$ with the aid of a peristaltic pump (Figure 2). The experiments were conducted in triplicates.

\section{FIGURE 2}

Aiming to elucidate the synergistic effect for all processes that compose PEO process, direct photolysis (DP), heterogeneous photocatalysis (HP) and electrochemical oxidation (EO) assays were performed under the same conditions of the PEO process in the same reactor. The 
difference between the processes were: In DP process, it was removed both catalysts and the current source. For HP process, only the current source was not used. For EO process, the $250 \mathrm{~W}$ HPL-N was turned-off.

Before starting the degradation experiment by DP, HP, EO and PEO processes, a control experiment was carried out. The solution were placed in the reservoir and the peristaltic pump fed the reactor at an average flow rate of $1 \mathrm{~L} / \mathrm{min}$ for $360 \mathrm{~min}$. The experimental was accomplished at room temperature, in dark and without the current source to elucidate whether the hydrolysis could significantly mineralize the antibiotics tested.

After the solution treatment, $\mathrm{pH}$ and TOC were analyzed according to the methods presented on 2.1.1 Chemical characterization.

The treatment efficiency was evaluated by calculating the TOC abatement (mineralization) and the energy consumption.

The conversion of TOC $(X, \%)$ was calculated according to equation (3):

$X(\%)=$ TOC $_{0}-$ TOC $/$ TOC $_{0} \times 100$

where $T O C_{O}$ is the TOC at the initial time and TOC is the TOC measurement at the $n$ time of treatment.

Two-way ANOVA was used to evaluate the influence of treatment methods and time in the mineralization of the antibiotics AMX, NOR and AZI: factor A - time - with seven levels $(a=7)$ and factor B - treatment methods - with four levels $(b=4)$.

The electric energy $\left(E_{E O}\right)$, in kilowatt hours $(\mathrm{kWh})$, required to degrade a contaminant by one order of magnitude in a unit volume of $1 \mathrm{~m}^{3}$ of contaminated water, has been described in a technical report: figures-of merit for the technical development and application of advanced oxidation technologies for both electric- and solar-driven system. In this technical report [34] $E_{E O}$ can be calculated by equation (4):

$E_{E O}=P \times t_{h} \times 1000 / V \times \log \left(T O C_{0} / T O C\right)$

where $P$ is the nominal power of the cell $(\mathrm{kW})$ and $t_{h}$ is the treatment time in hours (h). 


\section{RESULTS AND DISCUSSION}

\subsection{Solutions characterization}

\subsubsection{Electrochemical characterization}

Cyclic voltammetry (CV) experiments were performed in order to analyze the influence of the electrochemical (Figure 3a) and photo-assisted electrochemical (Figure 3b) oxidation process, on the direct and/or the mediated oxidation of the antibiotics AMX, NOR or AZI. Figure 3 shows no anodic neither cathodic peaks for the support electrolyte $\mathrm{Na}_{2} \mathrm{SO}_{4}$ and the solutions containing $A M X, N O R$ or $A Z I$, indicating that these antibiotics are not electro-active in the potential window used for this electrode [35], probably due to a weak interaction between this compound and the MOx surface.

When more positive potentials are achieved, the oxidation of water takes place on the surface of the mixed metal oxide $\left(\mathrm{MO}_{\mathrm{x}}\right)$ (eq. 5) with the hydroxyl radical ( $\mathrm{HO}{ }^{\bullet}$ ) generation (eq. 6) and concomitant oxygen evolution reaction (eq. 7) [36].

$\mathrm{MO}_{\mathrm{x}}+\mathrm{H}_{2} \mathrm{O} \rightarrow \mathrm{MO}_{\mathrm{x}}\left(\mathrm{HO}^{\bullet}\right)+\mathrm{H}^{+}$

$\mathrm{MO}_{\mathrm{x}}\left(\mathrm{HO}^{\bullet}\right) \rightarrow \mathrm{MO}_{\mathrm{x}+1}+\mathrm{H}^{+}$

$\mathrm{MO}_{\mathrm{x}+1} \rightarrow \mathrm{MO}_{\mathrm{x}}+1 / 2 \mathrm{O}_{2}$

Since no difference was detected between the support electrolyte and the antibiotics, difficulties can occur by the competition between the oxidation of organic compounds with the oxygen evolution reaction, leading to a decreased efficiency of the direct electrochemical degradation. In fact, with these results, only mediated electrochemical degradation reactions associated to the generation of radical species in the anode surface are expected.

When the $\mathrm{MO}_{\mathrm{x}}$ was assisted by UV radiation, an increase in the current density was observed in figure $3 \mathrm{~b}$. This fact was associate to the irradiation of $\mathrm{TiO}_{2}$ using light in a specific wavelength

$(\lambda \leq 400 \mathrm{~nm})$, that can promote an electron $\left(e^{-}\right)$from the valence band (VB) to the conduction 
band $(C B)$ with the consequent generation of a hole $\left(\mathrm{h}^{+}\right)$in the valence band. This phenomena was responsible to the observed current density increase.

$\mathrm{TiO}_{2}+h v \rightarrow e^{-}+\mathrm{h}^{+}$

FIGURE 3a and $b$

\subsubsection{UV absorbance spectra in water matrix}

The UV/Vis was performed on the stock solution at wavelengths between $190-900 \mathrm{~nm}$ in order to verify if the select antibiotics AMX, NOR and AZI are directly excited by absorbing energy from UV radiation. If that were the case, these antibiotics would be susceptible to degradation by direct UV radiation.

The results shows that the $\beta$-lactam AMX, fluoroquinolone NOR and macrolide AZI absorb UV radiation between 200 and $300 \mathrm{~nm}$. The absorbance maxima ( $\lambda$ max) for AMX are $230 \mathrm{~nm}$ and from 260 to $280 \mathrm{~nm}$, NOR has $\lambda$ max at 272 and from 260 to $280 \mathrm{~nm}$, while AZI do not exhibit distinct absorbance maxima under the experimental conditions. The absorption spectra for the selected antibiotics are shown in figure S2 (supplementary content).

Benotti et al. [17] and Kim et al. [19] have considered the use of UV radiation on the degradation of few antibiotics, concluding that only UV radiation was not effective for the degradation of these contaminants. In the same line, the result obtained by analyzing the UV spectra shows that the macrolide AZI have no $\lambda \max$, meaning that the influence of direct photolysis (DP) should be smaller than the one expected to the $\beta$-lactam AMX and to the fluoroquinolone NOR. This observation suggests the prevalence of the reactions between AZI and hydroxyl radicals. On the other hand, AMX and NOR are sensitive to direct photolysis by UV-C radiation, which may have a strong influence on the degradation of these compounds.

\subsection{System UV irradiation characterization}

In this section, the emission of the $250 \mathrm{~W}$ high-pressure commercial mercury vapor in UV-C spectra was evaluated. An intense peak in $254 \mathrm{~nm}$ and radiation emission in the same region of the absorption spectra of AMX and NOR (230 to $300 \mathrm{~nm}$ ) were detected (supplementary content, Figure S3). Therefore it is possible to expect that these two compounds will absorb UV radiation emitted by the lamp and will be degraded by direct photolysis. 
Table 1 show the Fluence rate incident in the ultrapure water and in the initial solution containing the antibiotics AMX, NOR and AZI. It is possible to see that the antibiotics AMX, NOR and AZI absorb $224 \mathrm{~kJ} / \mathrm{m}^{2}(27.4 \%), 66 \mathrm{~kJ} / \mathrm{m}^{2}(8 \%)$ and $14 \mathrm{~kJ} / \mathrm{m}^{2}$ (1.7\%), respectively.

These results demonstrate that in the Photo-assisted electrochemical process, the antibiotic AMX and NOR are degraded by direct photolysis and this phototransformation can be an important degradation pathway. Furthermore, the fluence that reaches the anode surface through the initial solution is higher than the one absorbed by the antibiotics, i.e. the photocatalytic process (HP) is favored in both cases. On the other hand, for the AZI, there was no significant difference between the fluence that reaches the ultrapure water and the initialsolution containing AZI.

\section{TABLE 1}

\subsection{Treatment efficiency evaluation}

The mineralization is an important parameter for the overall determination of organic pollution, since, through the TOC analysis, one can monitor the mineralization of the contaminants of emerging concern $\mathrm{AMX}, \mathrm{NOR}$ and $\mathrm{AZI}$, i.e. the degradation until $\mathrm{CO}_{2}, \mathrm{H}_{2} \mathrm{O}$ and inorganic ions.

By the control experiment it was observed that no significant mineralization was achieved in dark (supplementary content, Figure S4) and this found is in agreement with the literature [37]. Moreover, studies report that AMX ( $\mathrm{pKa}=3.2$ and 11.7$)$ and $A Z I(p K a=8.74)$ could undergo hydrolysis in environmental conditions [6] due to interactions with photosensitizers, but it was not expected hydrolysis for NOR (pKa $=8.6$ and 10.6).

Figure 4a shows a mineralization of $62 \%, 60 \%$ and $40 \%$ for AMX, NOR and AZI respectively at the final treatment time of 360 minutes. The lowest mineralization of AZI, when compared to the AMX and NOR values, can be explained by the spectra obtained by UV/Vis (supplementary content, Figure S2) and by the Fluence rate (table 1) results. The UV/Vis showed that the macrolide antibiotic AZI absorbs a low UV radiation, probably due to the lack of chromophore groups in the saturated aliphatic ring system. The Fluence rate $\left(\mathrm{kj} / \mathrm{m}^{2}\right)$ results demonstrated no significant difference between ultrapure water and the solution containing AZI. Some studies have also concluded that UV radiation alone was not effective enough for the degradation of macrolide contaminants [17-19]. Although by these results it was not expected any mineralization of the AZI, 
in this work, it is demonstrated that in fact AZI undergoes a small direct photolysis with $40 \%$ of mineralization. These results can be linked to the high Fluence rate emitted by the radiation source that can induce an excited electronic state at the dimethylamine group leading to photodegradation [38]. Likewise, Batchu et al. [31] did not observe any absorption peak for a macrolide solution but related photodegradation of erythromycin macrolide when using mercury vapor lamps (UV 254nm).

On the other hand, the $\beta$-lactam AMX and the fluoroquinolone NOR showed UV-C higher absorption in the UV/Vis spectra (supplementary content, Figure S2), precisely in the emission spectrum of the UV radiation source used. According to Qiang and Adams [39], the DP processes for NOR firstly start by the piperazine chain that have two ionisable nitrogen atoms with a pKa values of 8.6 and 10.6. These are the ones that can be firstly photodegradated, being the piperazine substituted by an amino compound. On the other hand, by the AMX, the more easily ionisable atoms are the ones present at the $\beta$-lactam ring followed by the ring opening [40]. Consequently, the initial solution containing these contaminants absorbed an important radiation value, demonstrating that theses antibiotics undergo higher phototransformation.

Figure $4 \mathrm{~b}$ shows that the AMX (49\%), NOR (51\%) and AZI (35\%) mineralization decreased with the addition of the two catalysts (70-30\%) $\mathrm{TiO}_{2} \mathrm{RuO}_{2}-\mathrm{Ti}$ and $\mathrm{TiO}_{2}-\mathrm{Ti}$, when compared to DP process. This results was observed in all experimental replications carried out as observed by the error bars on figures $4 a, b, c$ and $d$. Once the catalysts were added in the reaction system, they absorbed high amount of light (table 1), and less photons are available to be absorbed by the antibiotic molecules, decreasing the photolytic degradation. On the other side, the photons, absorbed by the catalyst in HP process, promote the $e^{-} / \mathrm{h}^{+}$separation, generating reducing and oxidizing sites (Eq. 8), which are able to catalyze the $\mathrm{HO}^{\bullet}$ generation. In this sense, it is expected an increase in the mineralization due to $\mathrm{HO}^{\bullet}$ formation. This fact was already observed in a study involving the degradation and mineralization of surfactant nonylphenol [30]. However, studies were conducted using a high pollutant concentrations (10 to $200 \mathrm{mg} / \mathrm{L}$ ) [11, 21, 30].

In the present work, the antibiotics, present in $\mu \mathrm{g} / \mathrm{L}$, should adsorb on a fixed number of active sites to react with $\mathrm{HO}^{\bullet}$, leading to mineralization. However, Langmuir-Hinshelwood model for heterogeneous photocatalysis (equation 19), postulates that the reaction of the species adsorbed on the surface is the rate-limiting step (Kumar et al. 2008). In this context, a low amount of antibiotics contaminant will be mineralized with the $\mathrm{HO}^{\bullet}$. As a consequence, the recombination of $e^{-} / \mathrm{h}^{+}$is favored, leading to a decrease in the TOC abatement (mineralization) and in the 
reaction rate (Eq. 9) [41, 42], when compared to DP processes, which is not limited by mass transport.

$e^{-}+\mathrm{h}^{+} \rightarrow \mathrm{N}(\mathrm{N}=$ neutral center $)$

Electrochemical Oxidation (EO) assays were performed under the same conditions of the PEO process in the same reactor without UV radiation by using a $250 \mathrm{~W}$ HPL-N lamp. Figure 4c shows small mineralization for AMX (24\%), NOR (24\%) and AZI (19\%). Although studies indicated that AZI undergo electronic interactions with transition metals [43], the voltammetry study showed no interaction between the work electrode (70-30\%) $\mathrm{TiO}_{2} \mathrm{RuO}_{2}-\mathrm{Ti}$ and the macrolide AZI, leading to believe that the TOC abatement of AZI, AMX and NOR occur manly by the oxidizing radicals generated by the $\mathrm{MO}_{\mathrm{x}}$ electrode, being this results in accordance with the literature [44]. The low mineralization can be explained by the low antibiotic concentration in the solution (200 $\mu \mathrm{g} / \mathrm{L}$ ), and, in these conditions, the systems are kinetically limited by mass transport [45]. On the other hand, when the EO system is under UV radiation (PEO process), the mass transfer limitations of the species are overcome, then a superior TOC removal value was obtained in figure $4 \mathrm{~d}$.

The increase in the mineralization for PEO process could be also explained by a decrease in the recombination of the $e^{-} / h^{+}$pair on the $\mathrm{TiO}_{2}$ phase of the $\mathrm{MO}_{\mathrm{x}}$ electrode (Eq. 9). When there is an application of a current or potential the $e^{-} / h^{+}$recombination can be avoid. Then these carriers can react with adsorbed $\mathrm{H}_{2} \mathrm{O}$ (Eq. 10) and $\mathrm{O}_{2}$ (Eq. 11 and 12) to generate hydroxyl radical (Eq. 13) [46]:

$e^{-}+\mathrm{H}_{2} \mathrm{O} \rightarrow \mathrm{H}_{2}+\mathrm{OH}^{-}$

$e^{-}+\mathrm{O}_{2} \rightarrow \mathrm{O}_{2}^{-}$

$h^{+}+\mathrm{H}_{2} \mathrm{O} \rightarrow 1 / 2 \mathrm{O}_{2}+2 \mathrm{H}^{+}$

$h^{+}+\mathrm{OH}^{-} \rightarrow \mathrm{HO}^{\bullet}$

According to Chong et al. [47], the $\mathrm{O}_{2}$ adsorbed onto $\mathrm{MO}_{\mathrm{x}}$ have an electron scavenger nature, allowing the formation of superoxides radical $\left(\mathrm{O}_{2}^{\cdot-{ }^{-}}\right)$(Eq. 14). Consequently, the recombination of the $e^{-} / h^{+}$pair also decrease.

$\left(\mathrm{O}_{2}\right)_{\mathrm{ads}}+e^{-} \rightarrow \mathrm{O}_{2}^{--}$ 
Still, $\mathrm{O}_{2}^{\bullet}$ can be protonated to form $\mathrm{H}_{2} \mathrm{O}_{2}$ (Eq. 15-17), that can act with organic pollutants [40] or UV irradiation can mediate the hydroxyl radical formation by $\mathrm{H}_{2} \mathrm{O}_{2}$ degradation (Eq. 18) [48].

$\mathrm{O}_{2}^{\bullet-}+\mathrm{HO}^{\bullet} \rightarrow \mathrm{HOO}^{\bullet}$

$\mathrm{HOO}^{\bullet}+e^{-} \rightarrow \mathrm{HO}_{2}^{-}$

$\mathrm{HOO}^{-}+\mathrm{H}^{+} \rightarrow \mathrm{H}_{2} \mathrm{O}_{2}$

$\mathrm{H}_{2} \mathrm{O}_{2}+h v \rightarrow 2 \mathrm{HO}^{\bullet}$

In fact, AMX and NOR presented a higher mineralization then AZ and no significant difference among each other in TOC abatement was observed, meaning that, for AMX and NOR, the radicals generated by the combination of photocatalyst, current applied and direct photolysis are responsible for the antibiotics degradation and TOC abatement.

FIGURE $4 a, b, c$ and $d$

The initial $\mathrm{pH}$ of the solution containing AMX, NOR and AZI without any adjust was $4.5 \pm$ 0.2. After the treatment time of $360 \mathrm{~min}$ for all processes, a significant difference in $\mathrm{pH}$ values was not observed. However a small decrease in $\mathrm{pH}$ from $4.5 \pm 0.2$ to $3.5 \pm 0.3$ was observed (supplementary content, Figure S5). This decrease in $\mathrm{pH}$ may be related to the fact that there was no $100 \%$ mineralization and that the degradation of many organic products leads to organic acids generation [30].

Two-way ANOVA was used to evaluate the influence of each method in the mineralization of antibiotics AMX, NOR and AZI. In Two-way ANOVA, for each hypothesis test it was computed the $\mathrm{F}$ tabulated (Ftab) of the Fisher distribution (F-distribution) and this was compared to the $\mathrm{F}$ calculated (Fcalc). If Fcalc > Ftab, then the null hypothesis is rejected and therefore the change in levels of the analyzed factors has a significant effect on the mean response. It means that, if Fcalc > Ftab, or $p$-value $<0.05(\alpha=5 \%)$, the effect studied is significant for a confidence level of 95 percent $[49,50]$. The results showed that for the parameter methods (PEO, HP, DP and EO) the Fisher distribution resulted in Fcalc > Ftab for all methods, indicating that the method type is significant for antibiotic mineralization (data presented on supplementary content, Tables S4, S5 and S6).

Insert graphics in figures $5 a, b, c$ and $d$ show that for all processes, the natural logarithm of $\left(\mathrm{TOC} / \mathrm{TOC}_{0}\right)$ as function of the treatment time is linear. Therefore, the reaction kinetics follows a 
first order kinetics. Accordingly, the model of Langmuir-Hinshelwood [51] can simulate the reaction kinetics for photolytic and catalytic [52] processes by the following equation:

$k \times t_{\text {min }}=-\ln \left(\right.$ TOC $/$ TOC $\left._{0}\right)$

were $k$ is the kinetic reaction rate $(1 / \mathrm{min})$ and $t_{\min }$ is the treatment time in minutes ( $\left.\mathrm{min}\right)$.

The slope of the straight line for an insert plot in figures $5 a, b, c$ and $d$ determines the $k$ value, which are summarized in table 2 . As can be seen in data of the table 2 , the experimental data fits reasonably well $\left(R^{2}=0.9\right)$ for all processes with the proposed Langmuir-Hinshelwood model.

Evaluating the data in table 2 and the results achieved so far it is noted that photolytic process occurred in the solution bulk and it was responsible for the high removal rates when compared to photocatalytic and electrochemical process, as that reaction is not limited by masstransport. Besides that, highest reaction rates were attained when the electrochemical process was assisted by UV radiation (PEO process), due to the direct phototransformation of AMX, NOR and AZI that seemed to suppress the mass transport limitations in electrochemical process.

Scaling-up the process for an industrial use, it will be necessary the calculation of the electric energy consumption which is an important parameter for the overall cost of the process. Considering that all processes exhibited a first order kinetics, the $E_{E O}$ from equation 4 can be rewritten by:

$E_{E O}=38.4 \times P / V \times k$

where 38.4 is the factor that corresponds to $1000 \times \ln (10) /(60)[34]$.

Table 2 also shows the $E_{E O}$ values for the different processes studied. The values found are not low because of the low reaction rate (low contaminant concentration) and of the incorporation of UV lamp (250W HPL-N) which may considerably increase the energy consumption of water treatment [34, 53]. Nevertheless, this calculation does not consider the system's efficiency in the antibiotics mineralization. Although Electrochemical Oxidation (EO) shows a low TOC abatement for AMX, NOR and $A Z I$ and has shown the lowest $E_{E O}$ value, it was not possible to achieve TOC removal above $50 \%$ in this system.

The photo-assisted electrochemical oxidation (PEO) was good to remove antibiotics compounds and other organic contaminants [30,54-56]. In this work, PEO process was the most energy efficient process, showing the highest mineralization rate, when compared to the other 
processes tested. This finding can be explained by a synergistic effect of combining the DP, HP and EO processes that leads to a powerful oxidation mechanism of the antibiotics AMX, NOR and AZI. Besides that, the $E_{E O}$ values found for the PEO process were lower than the $E_{E O}$ found by other authors $[57,58]$.

\section{TABLE 2}

\section{CONCLUSIONS}

This work demonstrated that the aqueous solution containing the three antibiotics group one $\beta$-lactam AMX, one fluoroquinolone NOR and another macrolide AZI, can be treated by the UV-based hybrid process PEO, showing a mineralization rate of $75 \%, 76 \%$ and $52 \%$, respectively.

Similar results were found after the final treatment time between AMX and NOR for the mineralization, kinetics and energetic consumption. These results can be explained by the similar molecular structure between the $\beta$-lactam and fluoroquinolone. Both have a chromophore groups with $\lambda$ max in the UV-C spectra emitted by the UV radiation source ( $250 \mathrm{~W}$ HPL-N). These results show that direct phototransformation (DP) is an important mineralization mechanism in the AMX and NOR, leading a different abatement pathway than the one associated to AZI.

Besides that, a limitation in the mass transport due to the low contaminants concentration $(200 \mu \mathrm{g} / \mathrm{L})$ was found for electrochemical oxidation (EO) and for heterogeneous photocatalysis (HP) processes and this limitation is overcome when these processes were combined (originating the hybrid process PEO) leading to a synergetic effect on mineralization. The PEO can be seen as an alternative method to the mineralization of antibiotics.

\section{ACKNOWLEDGEMENTS}


The authors thanks CAPES/DGPU-2015 project $n$ ㅇ 7595/14-0, CNPq, FAPERGS, Cyted and FINEP for the financial support.

\section{REFERENCES}

[1] R. Hirsch, T. Ternes, K. Haberer, K.-L. Kratz, Occurrence of antibiotics in the aquatic environment, Sci.Total Environ., 225 (1999) 109-118.

[2] K. Kummerer, Significance of antibiotics in the environment, J.Antimicrob.Chemoth., 52 (2003) 5-7.

[3] M.S. Diaz-Cruz, M.J. López de Alda, D. Barceló, Environmental behavior and analysis of veterinary and human drugs in soils, sediments and sludge, TRAC-Trend. Anal. Chem., 22 (2003) 340-351.

[4] R.N.C. Carvalho, L., A.L. Ippolito, T., Development of the first Watch List under the Environmental Quality Standards Directive, in, European Commission, 2015.

[5] L. Riaz, T. Mahmood, A. Khalid, A. Rashid, M.B. Ahmed Siddique, A. Kamal, M.S. Coyne, Fluoroquinolones (FQs) in the environment: A review on their abundance, sorption and toxicity in soil, Chemosphere, 191 (2018) 704-720.

[6] K. Hirte, B. Seiwert, G. Schüürmann, T. Reemtsma, New hydrolysis products of the beta-lactam antibiotic amoxicillin, their pH-dependent formation and search in municipal wastewater, Water Res., 88 (2016) 880888.

[7] D. Barcelo, J. Bennett, Antibiotic Resistance in the Environment, in: D. Barcelo, J. Bennett (Eds.), Science of the Total Environment, 2015.

[8] T.A. Larsen, J. Lienert, A. Joss, H. Siegrist, How to avoid pharmaceuticals in the aquatic environment, J. Biotechnol., 113 (2004) 295-304.

[9] M.O. Barbosa, N.F.F. Moreira, A.R. Ribeiro, M.F.R. Pereira, A.M.T. Silva, Occurrence and removal of organic micropollutants: An overview of the watch list of EU Decision 2015/495, Water Res., 94 (2016) 257279.

[10] J. Niu, L. Zhang, Y. Li, J. Zhao, S. LV, K. Xiao, Effects of environmental factors on sulfamethoxazole photodegradation under simulated sunlight irradiation: Kinetics and mechanism, J. Environ. Sci., 25 (2013) 1098-1106.

[11] M. Pazoki, M. Parsa, R. Farhadpour, Removal of the hormones dexamethasone (DXM) by Ag doped on TiO2 photocatalysis, J. Environ. Chem. Eng., 4 (2016) 4426-4434.

[12] Z. Wan, J. Hu, J. Wang, Removal of sulfamethazine antibiotics using CeFe-graphene nanocomposite as catalyst by Fenton-like process, J. Environ. Manage., 182 (2016) 284-291.

[13] R.B.P. Marcelino, M.M.D. Leão, R.M. Lago, C.C. Amorim, Multistage ozone and biological treatment system for real wastewater containing antibiotics, J. Environ. Manage., 195 (2017) 110-116.

[14] L. Zhu, B. Santiago-Schübel, H. Xiao, H. Hollert, S. Kueppers, Electrochemical oxidation of fluoroquinolone antibiotics: Mechanism, residual antibacterial activity and toxicity change, Water Res., 102 (2016) 52-62.

[15] G.G. Choudhry, G.R.B. Webster, Environmental photochemistry of polychlorinated dibenzofurans (PCDFs) and dibenzo-p-dioxins (PCDDs): A review, Toxicol. Environ. Chem., 14 (1987) 43-61.

[16] D. Juretic, H. Kusic, N. Koprivanac, A. Loncaric Bozic, Photooxidation of benzene-structured compounds: Influence of substituent type on degradation kinetic and sum water parameters, Water Res., 46 (2012) 3074-3084.

[17] M.J. Benotti, B.D. Stanford, E.C. Wert, S.A. Snyder, Evaluation of a photocatalytic reactor membrane pilot system for the removal of pharmaceuticals and endocrine disrupting compounds from water, Water Res., 43 (2009) 1513-1522.

[18] F. Yuan, C. Hu, X. Hu, J. Qu, M. Yang, Degradation of selected pharmaceuticals in aqueous solution with UV and UV/H2O2, Water Res., 43 (2009) 1766-1774. 
[19] I. Kim, N. Yamashita, H. Tanaka, Performance of UV and UV/H2O2 processes for the removal of pharmaceuticals detected in secondary effluent of a sewage treatment plant in Japan, J. Hazard. Mater., 166 (2009) 1134-1140.

[20] S.W. da Silva, C. Viegas, J.Z. Ferreira, M.A.S. Rodrigues, A.M. Bernardes, The effect of the UV photon flux on the photoelectrocatalytic degradation of endocrine-disrupting alkylphenolic chemicals, Environ. Sci. Pollut. R., (2016) 1-9.

[21] I.K. Konstantinou, T.A. Albanis, TiO2-assisted photocatalytic degradation of azo dyes in aqueous solution: kinetic and mechanistic investigations: A review, Applied Catalysis B: Environmental, 49 (2004) 1 14.

[22] J. Rivera-Utrilla, M. Sánchez-Polo, M.Á. Ferro-García, G. Prados-Joya, R. Ocampo-Pérez, Pharmaceuticals as emerging contaminants and their removal from water. A review, Chemosphere, 93 (2013) 1268-1287.

[23] A. Kapałka, G. Fóti, C. Comninellis, The importance of electrode material in environmental electrochemistry: Formation and reactivity of free hydroxyl radicals on boron-doped diamond electrodes, Electrochim. Acta, 54 (2009) 2018-2023.

[24] A. Kapałka, B. Lanova, H. Baltruschat, G. Fóti, C. Comninellis, Electrochemically induced mineralization of organics by molecular oxygen on boron-doped diamond electrode, Electrochem. Commun., 10 (2008) 1215-1218.

[25] Y. Einaga, J.S. Foord, G.M. Swain, Diamond electrodes: Diversity and maturity, MRS Bull., 39 (2014) 525-532.

[26] G. Fóti, C. Mousty, V. Reid, C. Comninellis, Characterization of DSA type electrodes prepared by rapid thermal decomposition of the metal precursor, Electrochim. Acta, 44 (1998) 813-818.

[27] S. Trasatti, Electrocatalysis: understanding the success of DSA ${ }^{\oplus}$, Electrochim. Acta, 45 (2000) 23772385.

[28] R. Pelegrini, P. Peralta-Zamora, A.R. de Andrade, J. Reyes, N. Durán, Electrochemically assisted photocatalytic degradation of reactive dyes, Appl. Catal. B-Environ., 22 (1999) 83-90.

[29] L. Pinhedo, R. Pelegrini, R. Bertazzoli, A.J. Motheo, Photoelectrochemical degradation of humic acid on a (TiO2)0.7(RuO2)0.3 dimensionally stable anode, Appl. Catal. B-Environ., 57 (2005) 75-81.

[30] S.W. da Silva, C.R. Klauck, M.A. Siqueira, A.M. Bernardes, Degradation of the commercial surfactant nonylphenol ethoxylate by advanced oxidation processes, J. Hazard. Mater., 282 (2015) 241-248.

[31] S.R. Batchu, V.R. Panditi, K.E. O'Shea, P.R. Gardinali, Photodegradation of antibiotics under simulated solar radiation: Implications for their environmental fate, Sci. Total Environ., 470-471 (2014) 299-310.

[32] A.G. Gonçalves, J.J.M. Órfão, M.F.R. Pereira, Ozonation of erythromycin over carbon materials and ceria dispersed on carbon materials, Chem. Eng. J., 250 (2014) 366-376.

[33] P. Liu, H. Zhang, Y. Feng, F. Yang, J. Zhang, Removal of trace antibiotics from wastewater: A systematic study of nanofiltration combined with ozone-based advanced oxidation processes, Chem. Eng. J., 240 (2014) 211-220.

[34] J.R. Bolton, K.G. Bircher, W. Tumas, C.A. Tolman, Figures-of merit for the technical development and application of advanced oxidation technologies for both electric- and solar-driven systems - (IUPAC Technical Report), Pure Appl. Chem., 73 (2001) 627-637.

[35] G. Li, M. Zhu, Y. Chen, Y. Li, X. Zhang, Production and contribution of hydroxyl radicals between the DSA anode and water interface, J. Environ. Sci., 23 (2011) 744-748.

[36] M.Panizza, G. Cerisola, Direct And Mediated Anodic Oxidation of Organic Pollutants, Chem. Rev., 109 (2009) 6541-6569.

[37] X.-Z. Niu, F. Busetti, M. Langsa, J.-P. Croué, Roles of singlet oxygen and dissolved organic matter in selfsensitized photo-oxidation of antibiotic norfloxacin under sunlight irradiation, Water Res., 106 (2016) 214222.

[38] M. Voigt, M. Jaeger, On the photodegradation of azithromycin, erythromycin and tylosin and their transformation products - A kinetic study, Sustainable Chemistry and Pharmacy, 5 (2017) 131-140.

[39] Z. Qiang, C. Adams, Potentiometric determination of acid dissociation constants (pKa) for human and veterinary antibiotics, Water Res., 38 (2004) 2874-2890. 
[40] R. Andreozzi, V. Caprio, C. Ciniglia, M. de Champdoré, R. Lo Giudice, R. Marotta, E. Zuccato, Antibiotics in the Environment: Occurrence in Italian STPs, Fate, and Preliminary Assessment on Algal Toxicity of Amoxicillin, Environ. Sci. Technol., 38 (2004) 6832-6838.

[41] I.K. Konstantinou, T.A. Albanis, TiO2-assisted photocatalytic degradation of azo dyes in aqueous solution: kinetic and mechanistic investigations, Appl. Catal. B-Environ., 49 (2004) 1-14.

[42] J.-M. Herrmann, Photocatalysis fundamentals revisited to avoid several misconceptions, Appl. Catal. Environm., 99 (2010) 461-468.

[43] J. Hartmann, P. Bartels, U. Mau, M. Witter, W.v. Tümpling, J. Hofmann, E. Nietzschmann, Degradation of the drug diclofenac in water by sonolysis in presence of catalysts, Chemosphere, 70 (2008) 453-461.

[44] D.A.C. Coledam, J.M. Aquino, B.F. Silva, A.J. Silva, R.C. Rocha-Filho, Electrochemical mineralization of norfloxacin using distinct boron-doped diamond anodes in a filter-press reactor, with investigations of toxicity and oxidation by-products, Electrochim. Acta, 213 (2016) 856-864.

[45] C.A. Martínez-Huitle, M.A. Rodrigo, I. Sirés, O. Scialdone, Single and Coupled Electrochemical Processes and Reactors for the Abatement of Organic Water Pollutants: A Critical Review, Chem. Rev., 115 (2015) $13362-13407$.

[46] B. Ohtani, Photocatalysis A to Z-What we know and what we do not know in a scientific sense, Journal of Photochemistry and Photobiology C: Photochemistry Reviews, 11 (2010) 157-178.

[47] M.N. Chong, B. Jin, C.W.K. Chow, C. Saint, Recent developments in photocatalytic water treatment technology: A review, Water Res., 44 (2010) 2997-3027.

[48] G. Li, W. Zhu, X. Chai, L. Zhu, X. Zhang, Partial oxidation of polyvinyl alcohol using a commercially available DSA anode, J. Ind. Eng. Chem., 31 (2015) 55-60.

[49] D.C. Montgomery, Introduction to statistical quality control, 2009.

[50] D.C. Montgomery, Design and Analysis of Experiments, 2012.

[51] K.V. Kumar, K. Porkodi, F. Rocha, Langmuir-Hinshelwood kinetics - A theoretical study, Catal. Commun., 9 (2008) 82-84.

[52] N. Daneshvar, M.H. Rasoulifard, A.R. Khataee, F. Hosseinzadeh, Removal of C.I. Acid Orange 7 from aqueous solution by UV irradiation in the presence of ZnO nanopowder, J. Hazard. Mater., 143 (2007) 95101.

[53] S. Hussain, J.R. Steter, S. Gul, A.J. Motheo, Photo-assisted electrochemical degradation of sulfamethoxazole using a Ti/Ru0.3Ti0.7O2 anode: Mechanistic and kinetic features of the process, J. Environ. Manage., 201 (2017) 153-162.

[54] A.N.A. Heberle, S.W. da Silva, C.R. Klauck, J.Z. Ferreira, M.A.S. Rodrigues, A.M. Bernardes, Electrochemical enhanced photocatalysis to the 2,4,6 Tribromophenol flame retardant degradation, J. Catal., 351 (2017) 136-145.

[55] S.W. da Silva, G.L. Bordignon, C. Viegas, M.A.S. Rodrigues, A. Arenzon, A.M. Bernardes, Treatment of solutions containing nonylphenol ethoxylate by photoelectrooxidation, Chemosphere, 119, Supplement (2015) S101-S108.

[56] Y. Xin, M. Gao, Y. Wang, D. Ma, Photoelectrocatalytic degradation of 4-nonylphenol in water with WO3/TiO2 nanotube array photoelectrodes, Chem. Eng. J., 242 (2014) 162-169.

[57] F.L. Souza, J.M. Aquino, D.W. Miwa, M.A. Rodrigo, A.J. Motheo, Photo-assisted electrochemical degradation of the dimethyl phthalate ester on $D A^{\circledR}{ }^{\circledR}$ electrode, J. Environ.I Chem. Eng., 2 (2014) 811-818.

[58] G. Hurwitz, E.M.V. Hoek, K. Liu, L. Fan, F.A. Roddick, Photo-assisted electrochemical treatment of municipal wastewater reverse osmosis concentrate, Chem. Eng. J., 249 (2014) 180-188. 


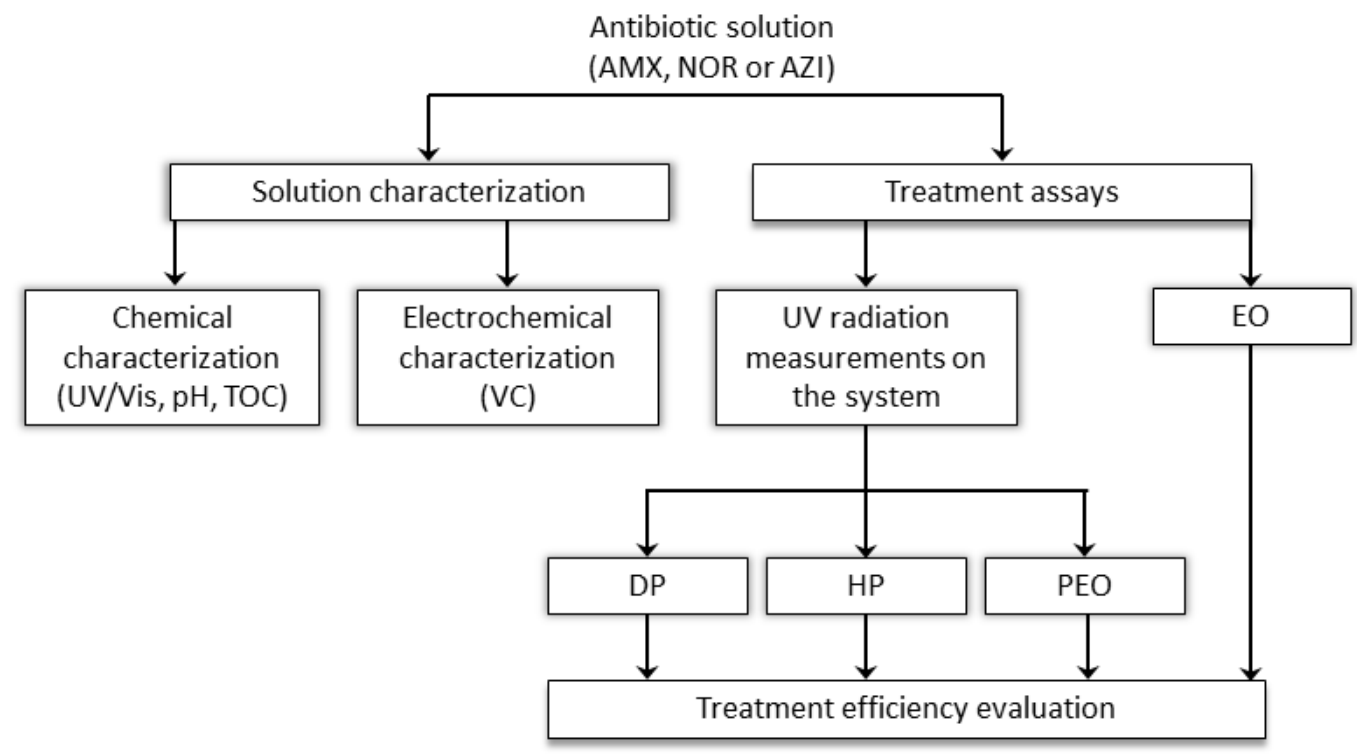

FIGURE 1. Experimental flowsheet used in this work.

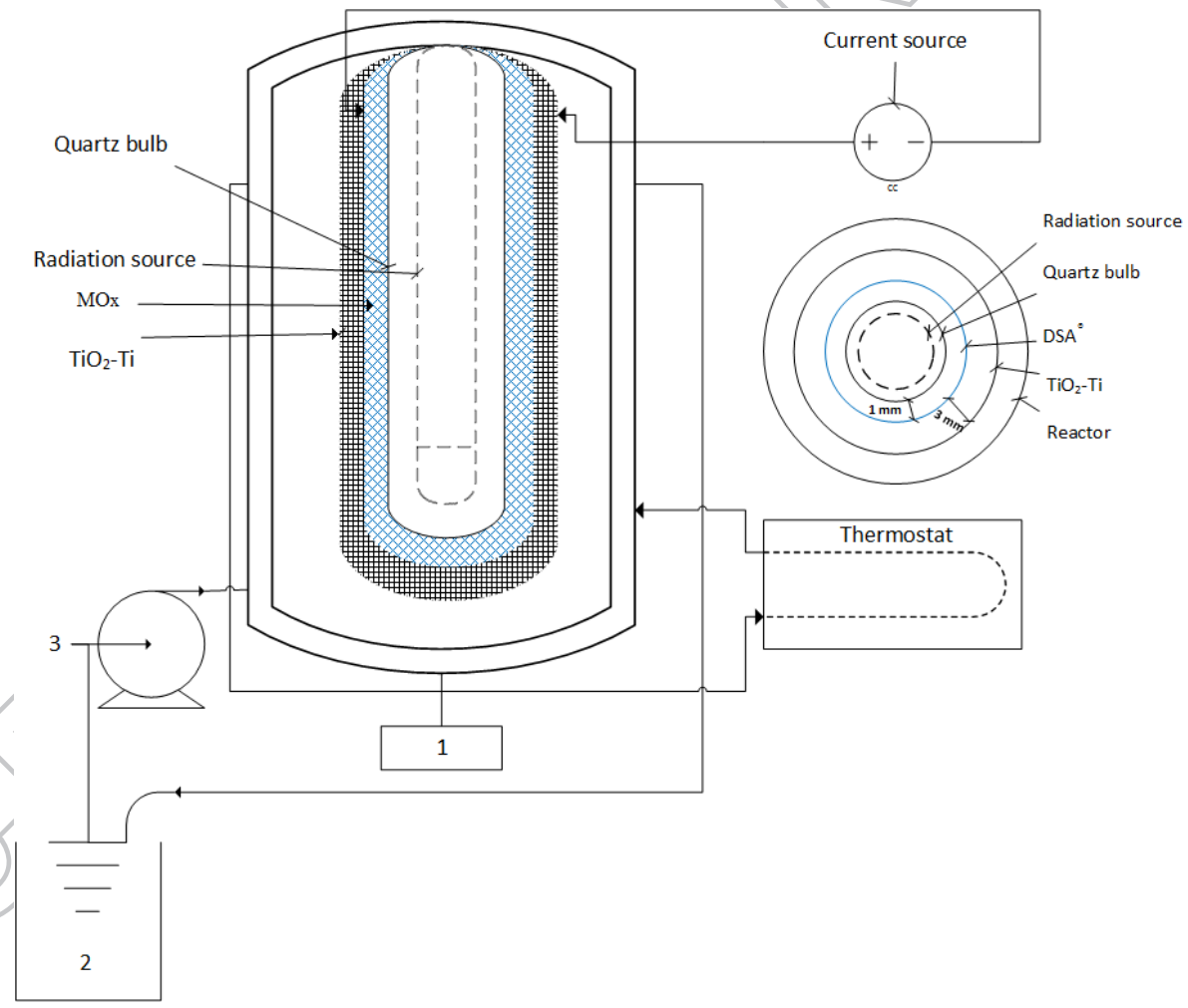

FIGURE 2. Reactor operated in batch mode with recirculation, where $\mathbf{1}$ is a jacket borosilicate glass reactor with capacity of $3 \mathrm{~L}, \mathbf{2}$ is a $5 \mathrm{~L}$ reservoir and $\mathbf{3}$ is a peristaltic pump [30]. 


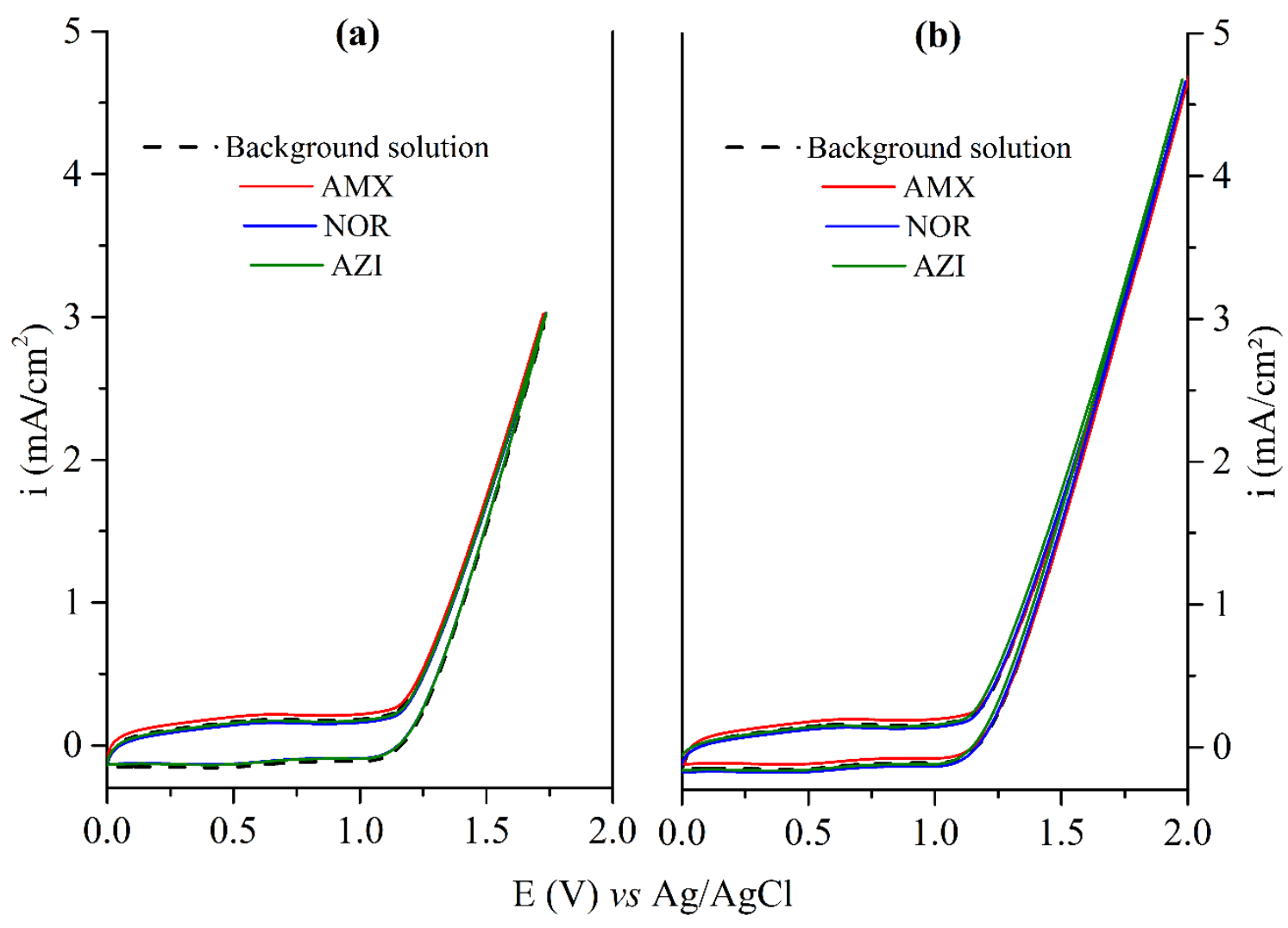

FIGURE 3. Cyclic voltammogram response of $\mathrm{MO}_{x}$ composed by (70-30\%) $\mathrm{TiO}_{2} \mathrm{RuO}_{2}-\mathrm{Ti}$ for the electrolyte solution containing $2 \mathrm{~g} / \mathrm{L}$ of $\mathrm{Na}_{2} \mathrm{SO}_{4}$ and stock solutions containing $100 \mathrm{mg} / \mathrm{L}$ of the antibiotics AMX, NOR or AZI in electrolyte solution containing $2 \mathrm{~g} / \mathrm{L}$ of $\mathrm{Na}_{2} \mathrm{SO}_{4}$. (a) not assisted by $U V$ radiation and (b) assisted by UV radiation. 


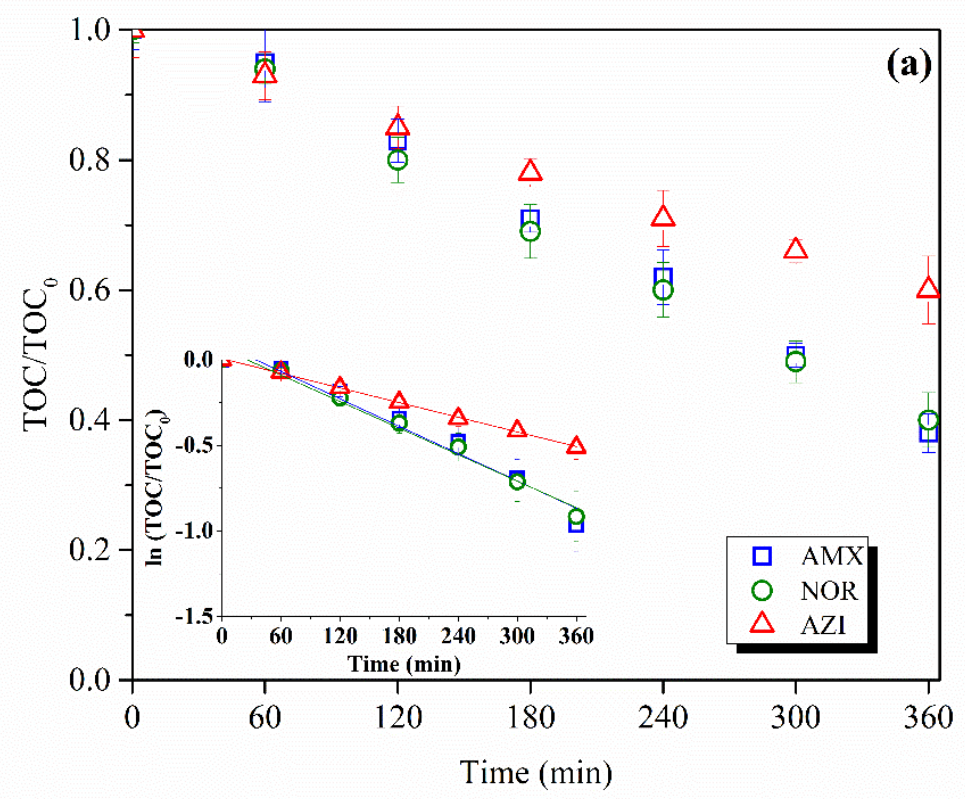

Figure 4 a

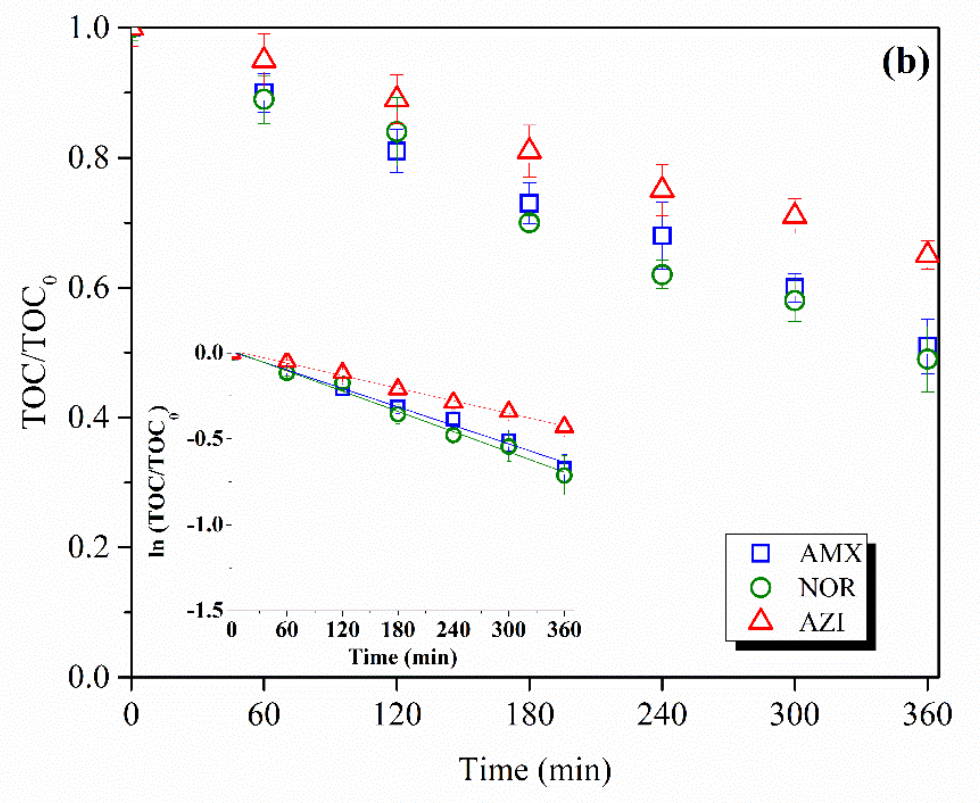

Figure $4 \mathrm{~b}$ 


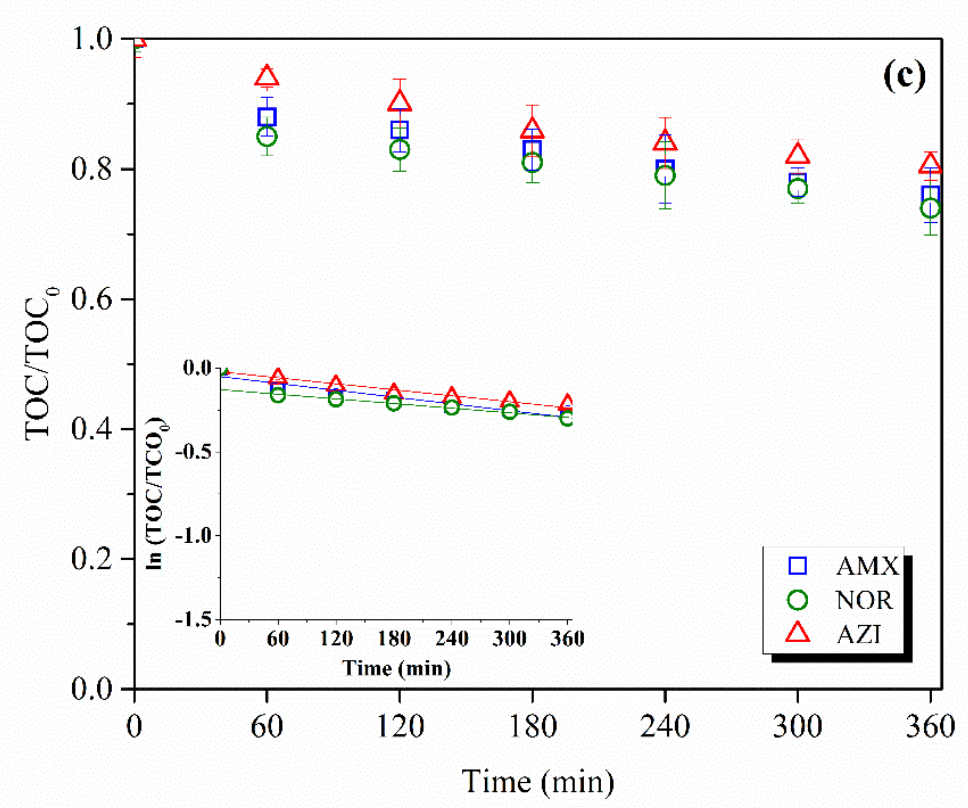

Figure $4 \mathrm{c}$

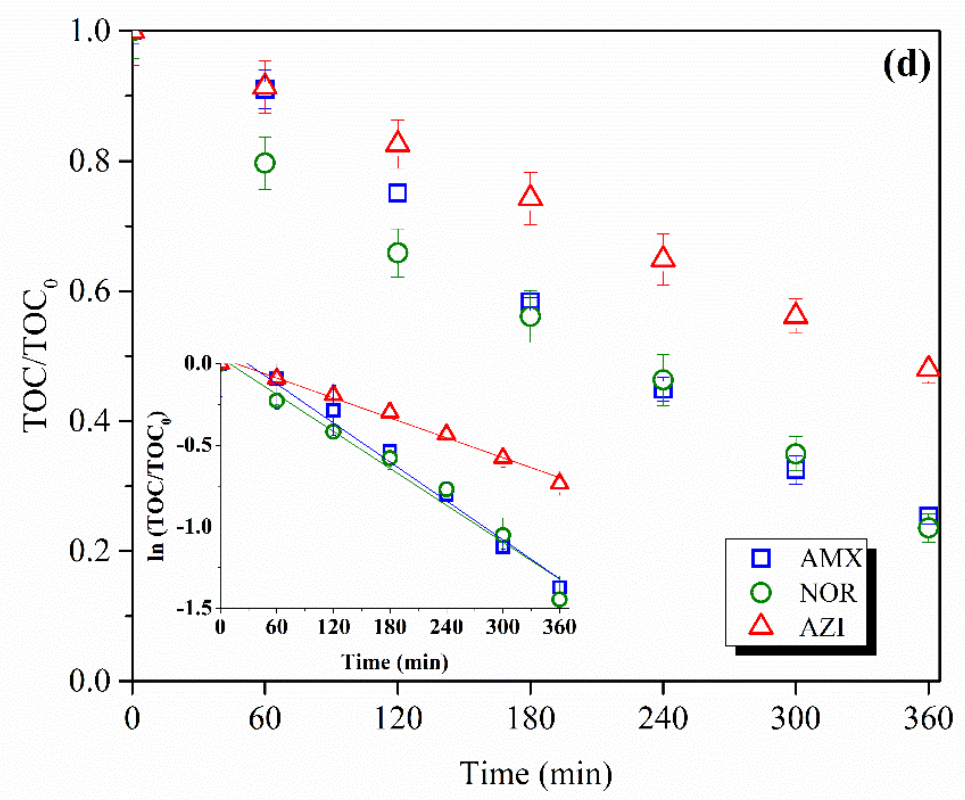

Figure $4 \mathrm{~d}$

FIGURE 4. Mineralization of solutions containing $A M X, N O R$ and $A Z I$ untreated and treated by Direct Photolysis (DP) (a), Heterogeneous Photocatalysis (HP) (b), Electrochemical oxidation (EO) (c) and Photo-assisted electrochemical oxidation (PEO) (d). Insert graphic is the LangmuirHinshelwood model plot of reaction rate. The initial conditions of the performed experiments were $200 \mu \mathrm{g} / \mathrm{L}$ of $\mathrm{AMX}, \mathrm{NOR}$ and $\mathrm{AZI}$ and $2 \mathrm{~g} / \mathrm{L}$ of $\mathrm{Na}_{2} \mathrm{SO}_{4} ; \mathrm{pH} \quad 4.5 \pm \frac{ \pm}{0.2}$. 
Table 1. Fluence rate incident on the electrodes surface by ultrapure water or by the work solution containing $A M X, N O R$ and $A Z I$. The initial conditions of the performed experiments were $200 \mu \mathrm{g} / \mathrm{L}$ of $\mathrm{AMX}, \mathrm{NOR}$ and $\mathrm{AZI}$ and $2 \mathrm{~g} / \mathrm{L}$ of $\mathrm{Na}_{2} \mathrm{SO}_{4} ; \mathrm{pH} 4.5 \pm 0.2$.

\begin{tabular}{|l|c|c|}
\hline & $\begin{array}{c}\text { Fluence rate incident on the electrodes surface } \\
\left(\mathbf{k j} / \mathbf{m}^{\mathbf{2}} \mathbf{)}\right.\end{array}$ & $\begin{array}{c}\text { Absorbed by work solution } \\
\left(\mathbf{k j} / \mathbf{m}^{\mathbf{2}}\right)\end{array}$ \\
\hline Ultrapure water & 818 & 0 \\
\hline Work solution containing AMX & 594 & 224 \\
\hline Work solution containing NOR & 752 & 66 \\
\hline Work solution containing AZI & 804 & 14 \\
\hline
\end{tabular}

Table 2. First-order kinetic rate constants for all processes using the Langmuir-Hinshelwood model, nominal power of the cell, conversion and the electric energy per order for the mineralization of the antibiotics AMX, NOR and AZI.

\begin{tabular}{|c|c|c|c|c|c|c|}
\hline Process name & Antibiotic & $k(1 / \mathrm{min})$ & $\mathbf{R}^{\mathbf{2}}$ & Nominal power of the cell $(\mathrm{kW})$ & $x(\%)$ & $\mathrm{E}_{\mathrm{EO}}\left(\mathrm{kWh} / \mathrm{m}^{3} / \mathrm{order}^{-1}\right)$ \\
\hline \multirow{3}{*}{$\begin{array}{l}\text { Direct Photolysis } \\
\text { (DP) }\end{array}$} & AMX & 0.0027 & 0.95 & 0,25 & 62 & 711 \\
\hline & NOR & 0.0026 & 0.98 & 0,25 & 60 & 738 \\
\hline & AZI & 0.0014 & 0.99 & 0,25 & 40 & 1371 \\
\hline \multirow{3}{*}{$\begin{array}{l}\text { Heterogeneous Photocatalysis } \\
\text { (HP) }\end{array}$} & AMX & 0.0018 & 0.98 & 0,25 & 49 & 1067 \\
\hline & NOR & 0.0019 & 0,98 & 0,25 & 51 & 1011 \\
\hline & AZI & 0.0012 & 0.99 & 0,25 & 35 & 1600 \\
\hline \multirow{3}{*}{$\begin{array}{l}\text { Electrochemical oxidation } \\
\text { (EO) }\end{array}$} & AMX & 0.00067 & 0.91 & 0,075 & 24 & 860 \\
\hline & NOR & 0.00068 & 0.91 & 0,075 & 26 & 847 \\
\hline & AZI & 0.00059 & 0.94 & 0,075 & 20 & 976 \\
\hline \multirow{3}{*}{$\begin{array}{l}\text { Photo-assisted electrochemical oxidation } \\
\text { (PEO) }\end{array}$} & AMX & 0.0040 & 0.97 & 0,325 & 75 & 624 \\
\hline & NOR & 0.0038 & 0.97 & 0,325 & 76 & 657 \\
\hline & AZI & 0.0020 & 0.98 & 0,325 & 52 & 1248 \\
\hline
\end{tabular}

